\title{
KONCEPCJA STANOWISKA DO POMIARÓW WSPÓŁCZYNNIKÓW WYMIANY MASY/CIEPŁA W MINI-WYMIENNIKACH
}

\begin{abstract}
W artykule zaprezentowano wstępną koncepcję stanowiska eksperymentalnego do badań wymiany masy/ciepła w elementach mini-wymienników ciepła. Proponowana metoda badawcza bazuje na technice elektrolitycznej, w której do wyznaczenia współczynników wymiany masy wykorzystuje się zależności opisujące zjawiska elektrolizy. Pomiary powstałych prądów granicznych, powierzchni katody, przy której następuje wymiana roboczych jonów, oraz stężenia jonów w elektrolicie, dają możliwość określenia intensywności wymiany masy. Otrzymane wielkości, wykorzystując analogię pomiędzy procesami przenoszenia masy i ciepła, przelicza się na współczynniki wymiany ciepła. Proponowana metoda może być również wykorzystywana w mini-skali. Wiąże się to jednak z dodatkowymi warunkami, które muszą być spełnione, aby zminimalizować błędy wynikające ze skali procesu, a związane m.in. z chropowatością powierzchni elektrod, zmianą stężenia na długości katody, czy też grubością średniej warstwy dyfuzyjnej. Zaprojektowane stanowisko będzie umożliwiało badania nad intensywnością wymiany masy/ciepła w mini-wymienniku ciepła z kanałami o przekroju prostokątnym.
\end{abstract}

Słowa kluczowe: badania eksperymentalne, metoda prądów granicznych, minikanały, wymiana ciepła

\section{Wstęp}

Procesy wymiany ciepła zachodzące w urządzeniach o małych wymiarach stanowią $\mathrm{w}$ dzisiejszych czasach istotne zagadnienie ze względu na powszechną miniaturyzację samych urządzeń oraz ich elementów. Badania prowadzone w zakresie zjawisk przekazywania ciepła w układach, których parametry geometryczne są znacznie mniejsze od konwencjonalnych, wykazują duże odstępstwa

\footnotetext{
${ }^{1}$ Autor do korespondencji: Sebastian Grosicki, Politechnika Rzeszowska, 35-959 Rzeszów, al. Powstańców Warszawy 12, tel. (17) 865-1326, e-mail: sebogr@prz.edu.pl

${ }^{2}$ Robert Smusz, Politechnika Rzeszowska, e-mail: robsmusz@ prz.edu.pl

${ }^{3}$ Joanna Wilk, Politechnika Rzeszowska, e-mail: joanwilk@prz.edu.pl
} 
od tychże zachodzących w typowych warunkach. W ostatnich dwóch dekadach bardzo szeroko rozwinęła się dyscyplina zajmująca się eksperymentalnymi badaniami w zakresie wymiany ciepła w mini i mikrokanałach. Dotyczy to kanałów okrągłych, jak również kanałów o innych przekrojach. Okazuje si, że uzyskiwane wyniki badań nie są spójne, można znaleźć zależności, na podstawie których wyznaczane współczynniki wymiany ciepła w minikanałach znacznie przewyższają dane dla kanałów konwencjonalnych, są od nich mniejsze lub też przyjmują wartości zbliżone jak dla warunków konwencjonalnych. Zestawienie danych literaturowych na ten temat można znaleźć m.in. w [6].

Najczęściej wykorzystywaną metodą $w$ badaniach eksperymentalnych wymiany ciepła jest metoda bilansu cieplnego, której zasadniczym elementem jest pomiar temperatury powierzchni wymieniającej ciepło z płynem oraz temperatury płynu. W skali mikro jest to bardzo trudne do wykonania ze względu na wielkości czujników pomiarowych porównywalne $\mathrm{z}$ wielkościami badanych elementów. Stanowi to jedną z przyczyn niedokładności uzyskiwanych wyników.

Przykładowe rezultaty przedstawione na rys.1 reprezentują skumulowane wyniki badań opisanych w [2] prowadzonych tradycyjną metodą bilansu cieplnego dla jednofazowego konwekcyjnego przepływu przez okrągły minikanał o średnicy $0.528 \mathrm{~mm}$ i długości $36.8 \mathrm{~mm}$. Badania dotyczyły warunku stałej gęstości strumienia ciepła na powierzchni ścianki. Linia ciągła przedstawia aproksymację rozwiązania analitycznego [8], której postać wyraża (1). Dane na rys.1 jak również zależność (1) reprezentują wartości miejscowych liczb Nusselta.

$$
N u_{x}=4.364+\frac{0.2633\left(\operatorname{Re} \operatorname{Pr} \frac{d}{x}\right)^{0.506}}{\exp \left[41\left(\operatorname{Re} \operatorname{Pr} \frac{d}{x}\right)^{-1}\right]} ; \operatorname{Re} \operatorname{Pr} \frac{d}{x}<1000
$$

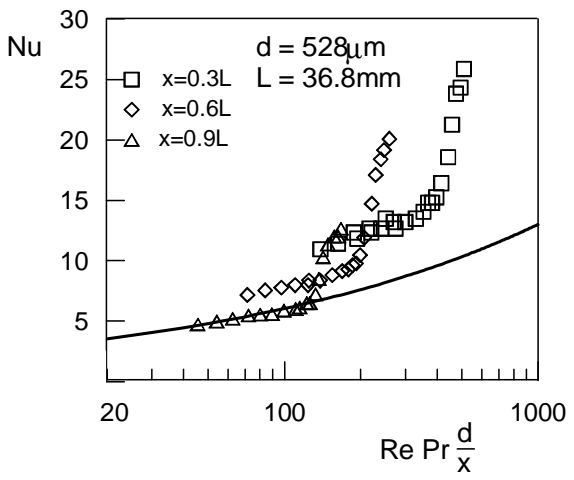

Rys. 1. Wyniki badań konwekcyjnej wymiany ciepła w minikanale (na podst.[2]) w porównaniu rozwiązaniem analitycznym

Fig. 1. Results of convective heat transfer in mini channel (prepared on the basis of [2]) with comparison of the analytical solution 


\section{Wykorzystanie metody prądów granicznych w analogii wy- miany ciepła i masy}

W przypadku badań przejmowania ciepła przy przepływie przez minikanały mogą wystąpić znaczne błędy pomiarowe wynikające z zakłóceń procesów konwekcyjnej wymiany ciepła spowodowanych m.in. montażem czujników temperatury, którymi najczęściej są termopary. W związku z tym istnieje konieczność poszukiwania innych technik badawczych, które zminimalizowałyby powyższe błędy. Jedną z nich jest metoda prądów granicznych znana również pod nazwą techniki elektrolitycznej, której podstawą jest pomiar wartości prądów granicznych powstających w procesach elektrolizy przebiegających w układzie z elektrolitem, gdzie powierzchnie katod stanowią elementy modelujące powierzchnię wymiany ciepła w zjawisku rzeczywistym. Szczegóły dotyczące podstaw teoretycznych techniki elektrolitycznej można znaleźć w [1].

Główną zależnością w metodzie prądów granicznych, na podstawie której oblicza się współczynniki wymiany masy jest

$$
h_{D}=I_{p} / n F A C_{b}
$$

gdzie: $I_{p}$ - natężenie prądu granicznego, $n$ - elektronowość reakcji elektrodowej, $F$ - stała Faradaya, $A$ - powierzchnia katody, $C_{b}$ - stężenie roboczych jonów w elektrolicie.

Wyznaczone na bazie (2) współczynniki wymiany masy $h_{D}$ przelicza się następnie na współczynniki wymiany ciepła stosując analogię procesów przenoszenia ciepła i masy. Procesy te mogą być opisane za pomocą równań różniczkowych identycznie skonstruowanych - jest to podstawa analogii. Aby jednak wystąpiła ścisła analogia tych procesów muszą być spełnione następujące warunki: nie występowanie radiacyjnej wymiany ciepła, brak lepkościowej dyssypacji energii, brak wpływu wymiany masy na profil prędkości przepływu oraz stałość właściwości fizycznych płynów [5]. Przy stosowaniu metody prądów granicznych, warunki te są spełnione.

Podstawową zależność wynikającą z analogii procesów wymiany ciepła i masy przy konwekcyjnym przepływie w kanałach można przedstawić w formie równania wiążącego odpowiednie liczby podobieństwa dla wymiany ciepła $\mathrm{z}$ analogicznymi dla wymiany masy

$$
N u / S h=(\operatorname{Pr} / S c)^{q}
$$

gdzie: $\mathrm{Nu}$ - bezwymiarowy współczynnik wymiany ciepła (liczba Nusselta), Sh - bezwymiarowy współczynnik wymiany masy (liczba Sherwooda), Pr, Sc odpowiednio liczba Prandtla i Schmidta reprezentujące właściwości termofi- 
zyczne płynów w procesach wymiany ciepła i masy. Stała $q$ wyznaczana eksperymentalnie może przyjmować różne wartości. W analogii Chiltona-Colburna [1], która będzie stosowana w przewidywanych badaniach $q=1 / 3$.

\section{Stanowisko do badań współczynników wymiany masy/ciepła w mini-wymienniku ciepła}

Badania wymiany masy/ciepła w elementach urządzeń energetycznych były dotychczas prowadzone na uniwersalnym stanowisku w laboratorium Katedry Termodynamiki i Mechaniki Płynów Politechniki Rzeszowskiej. W stanowisku tym, którego uproszczony schemat przedstawia rys.2, zasadniczą część stanowi sekcja pomiarowa, w której zamodelowany jest element wymieniający ciepło w zjawisku rzeczywistym, powierzchnię wymiany ciepła modeluje katoda, przy której zachodzą procesy elektrochemiczne odpowiedzialne za wymianę masy.

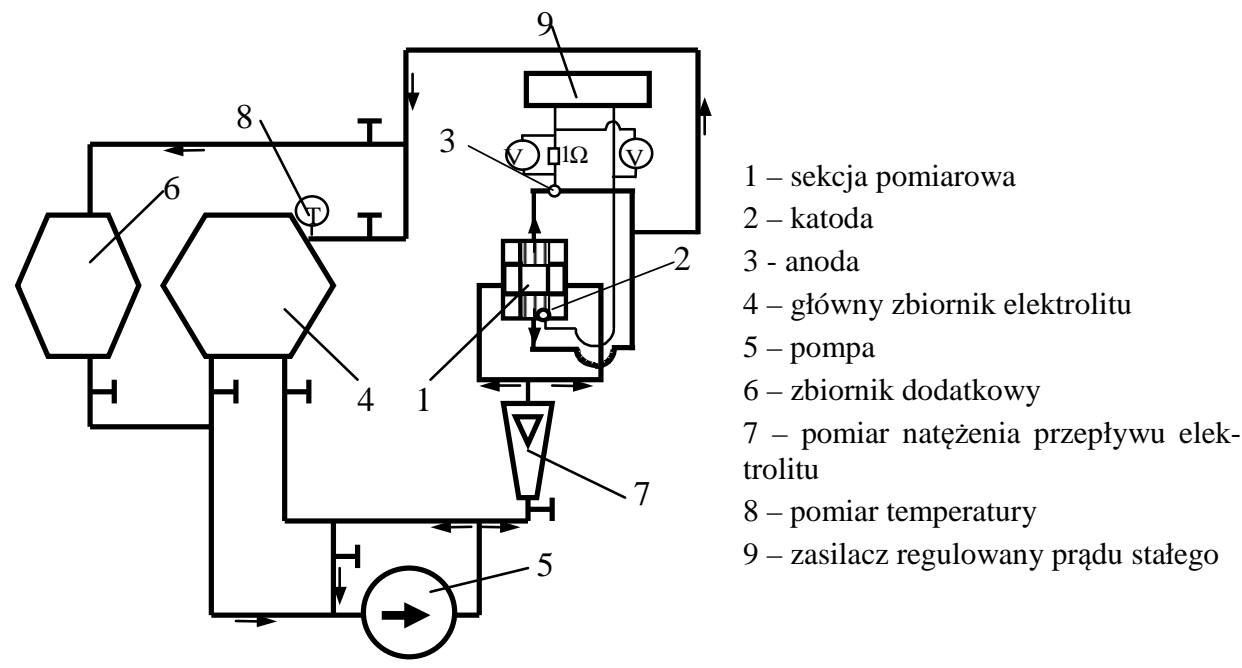

Rys. 2. Schemat stanowiska do badań elektrolitycznych pracującego w układzie zamkniętym $\mathrm{z}$ zaznaczonym kierunkiem przepływu elektrolitu

Fig. 2. Scheme of the test stand for electrolytic measurements in the closed system, the flow direction of the electrolyte is marked

Prezentowane stanowisko, pracujące w układzie zamkniętym (przepływ elektrolitu w układzie zamkniętym) służy zasadniczo do badań procesów wymiany masy/ciepła zachodzących w aparatach o wymiarach konwencjonalnych. Odpowiednie przystosowanie sekcji pomiarowej umożliwiło również eksperymenty w minikanałach $[6,7]$. Ze względu na warunki hydrauliczne, badania były prowadzone na modelowym pierścieniu $\mathrm{z}$ wydrążoną znaczną liczbą minikana- 
łów. Uzyskane wyniki zachęciły do dalszych badań elementów miniurządzeń, co z kolei zaowocowało koncepcją stanowiska przystosowanego wyłącznie do badań w mikro i mini-skali. Schemat takiego stanowiska prezentuje rys.3. Praca układu odbywa się w obiegu półotwartym, zużyty elektrolit będzie zbierany w specjalnym zbiorniku. Do układu będzie dostarczany azot w celu usunięcia tlenu z elektrolitu (tlen wywołuje dodatkowe reakcje chemiczne zniekształcające zasadniczy proces elektrolityczny, a tym samym powodujące błędne wyniki pomiarów współczynników wymiany masy). Do pomiaru natężenia przepływu elektrolitu przewiduje się przepływomierze zwężkowe, które zostaną specjalnie kalibrowane przy użyciu płynu o właściwościach elektrolitu w celu uzyskania odpowiednich charakterystyk przepływowych. Temperatura elektrolitu będzie utrzymywana na stałym poziomie za pomocą ultratermostatu, Jest to bardzo istotny element ze względu na konieczność zachowania stałości właściwości termofizycznych płynu jakim jest elektrolit. Aby nastąpiły reakcje redukcji przy katodzie modelującej powierzchnię wymiany ciepła, do układu musi być poda-

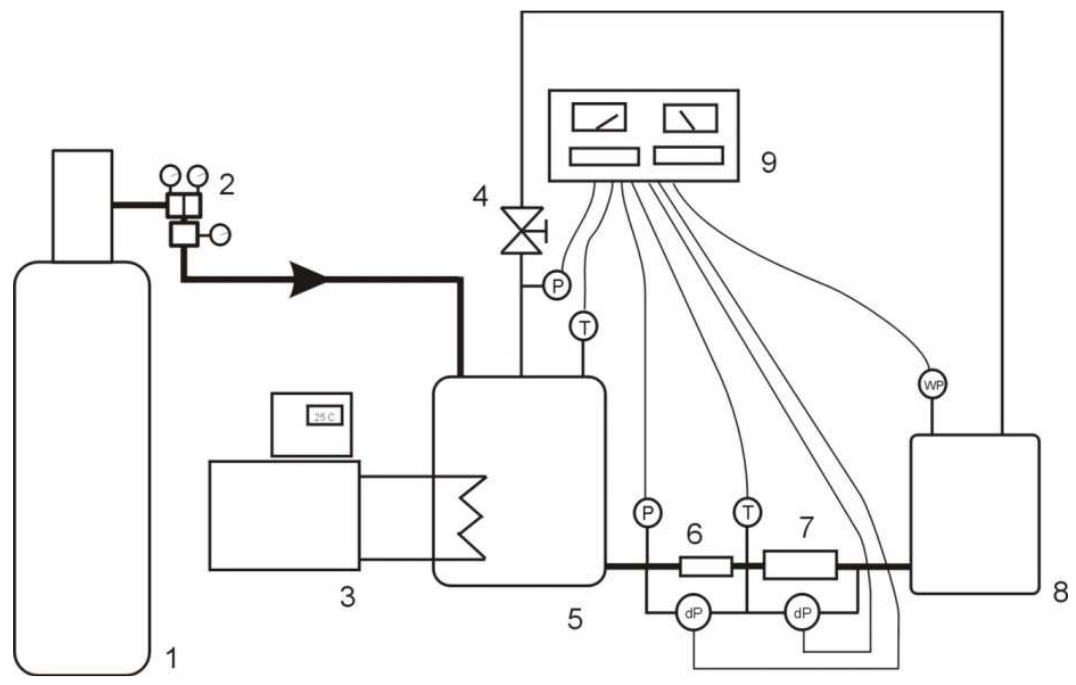

1 - butla z azotem, 2 - reduktor ciśnienia, 3 - ultratermostat, 4 - zawór, 5 - zbiornik z elektrolitem, 6 - przepływomierz zwężkowy, 7 - sekcja pomiarowa, 8 - zbiornik na zużyty elektrolit, 9 multimetr (system rejestracji i przetwarzania danych)

$\mathrm{T}$ - pomiar temperatury, $\mathrm{P}$ - przetworniki ciśnień, dP - przetworniki różnicy ciśnień, wp wskaźnik przepływu azotu

Rys. 3. Schemat stanowiska do badań elektrolitycznych w mini-skali pracującego w układzie zamkniętym z zaznaczonym kierunkiem przepływu elektrolitu

Fig. 3. Scheme of the test stand worked in the closed system for mini-scale electrolytic measurements, the flow direction of the electrolyte is marked 
wane napięcie. Wzrost napięcia powoduje wzrost natężenia prądu płynącego w obwodzie zewnętrznym do momentu kiedy następuje tzw. dyfuzja kontrolowana - stężenie jonów roboczych przy katodzie maleje do zera, natężenie prądu osiąga stałą wartość (prąd graniczny). Stosując prawa znane w elektrochemii dochodzi się do zależności (2) umożliwiającej wyznaczenie współczynników wymiany masy. Sterownie napięciem prądowym w układzie elektrycznym oraz zapis charakterystyk napięciowo-prądowych (woltamogramów) będzie się odbywało w sposób automatyczny przy wykorzystaniu multimetru umożliwiającego rejestrację i przetwarzanie danych.

Konstruowane stanowisko badawcze posłuży w pierwszej wersji do badań miniwymiennika, w którym konwekcyjna wymiana ciepła zachodzi podczas laminarnego przepływu czynnika przez zestaw od kliku do kilkunastu równoległych minikanałów o przekroju prostokątnym. Schemat sekcji pomiarowej prezentuje rys.4. Element pomiarowy wymiennika będzie wykonany z blachy niklowej o grubości $2 \mathrm{~mm}$. Po wklejeniu blachy w obudowę zostaną wyfrezowane rowki o wymiarach $1 \times 1 \mathrm{~mm}$ i długości $15 \mathrm{~mm}$, których powierzchnia wewnętrza będzie stanowiła katodę w procesach elektrochemicznych. Aby uzyskać niezbędną

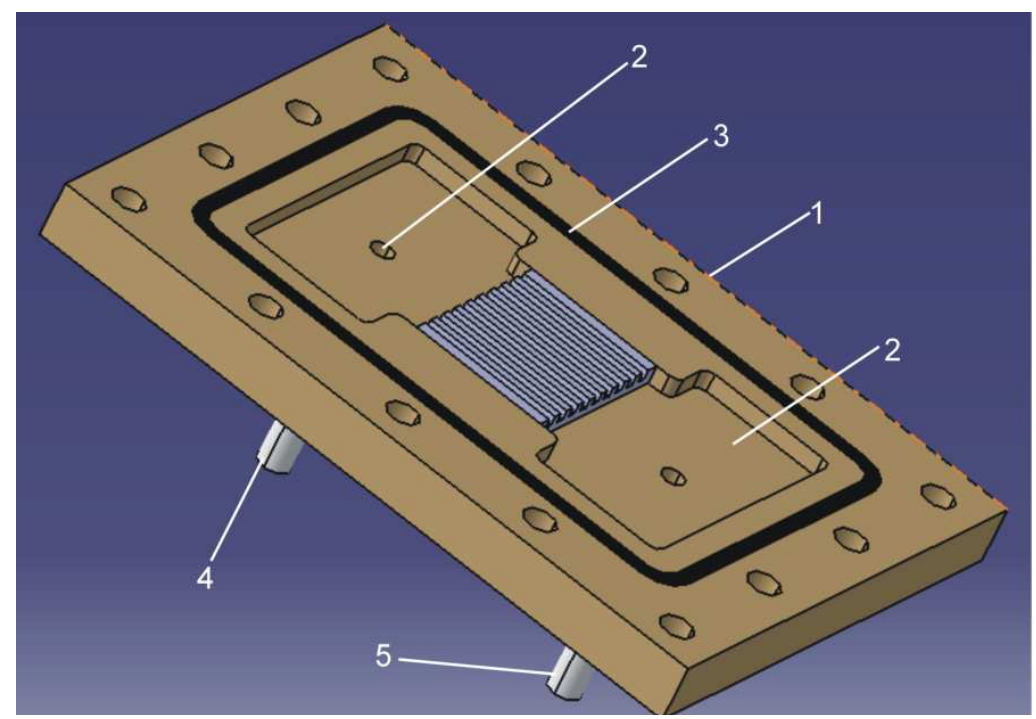

1 - obudowa, 2 - plenum, 3 - uszczelnienie, 4 - wlot elektrolitu, 5 - wylot elektrolitu

Rys. 4. Wizualizacja sekcji pomiarowej do badań elektrolitycznych mini-wymiennika ciepła

Fig. 4. Visualization of the test section for electrolytical investigations of the mini heat exchanger

gładkość powierzchni katody, w celu zminimalizowania wpływu chropowatości na wyniki badań, rowki będą następnie polerowane za pomocą specjalnych past diamentowych o niskiej ziarnistości. Obudowa będzie przykryta pokrywą zli- 
cowaną z płaszczyzną wymiennika dla zapewnienia szczelności sekcji pomiarowej. Wizualizację projektowanego mini-wymiennika przedstawia na rys.5.

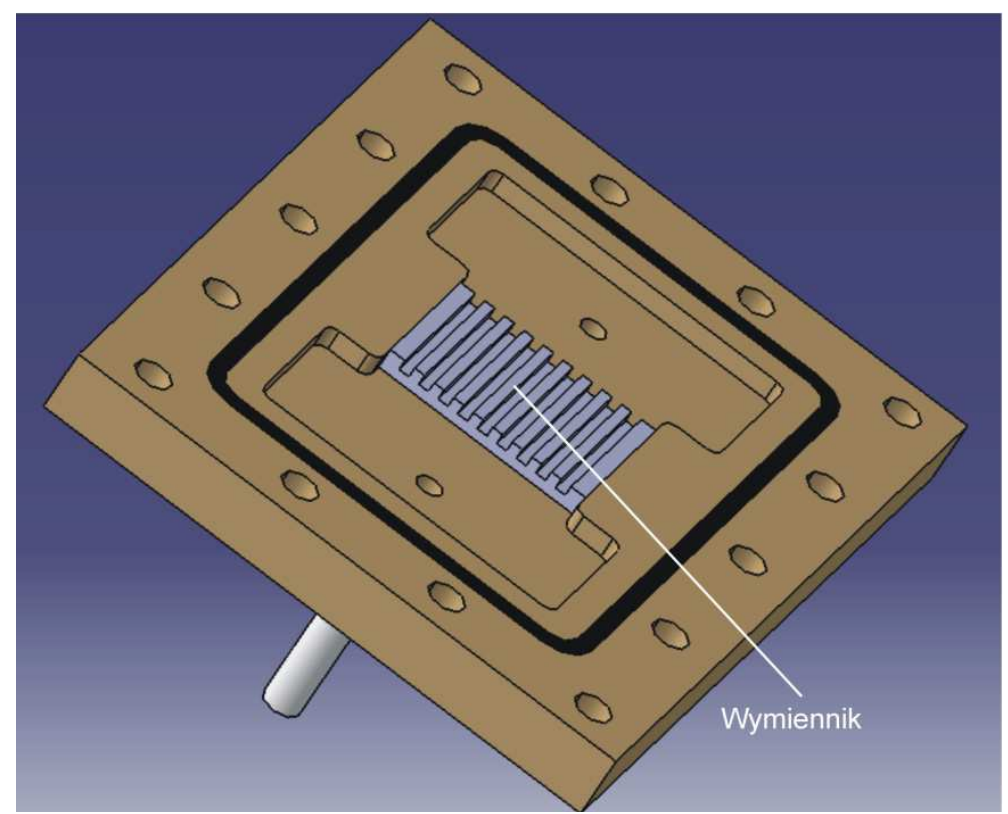

Rys. 5. Wymiennik ciepła z minikanałami o przekroju prostokątnym

Fig. 5. Heat exchanger with mini channels of rectangular cross-section

\section{Podsumowanie}

Projektowane stanowisko do pomiarów elektrolitycznych wymiany masy w miniskali będzie również w przyszłości wykorzystane do badań minikanałów o innych przekrojach. Pierwsza wersja zakładająca wymiennik o prostokątnych minikanałach ma swoje odniesienie w literaturze. Wyniki symulacji numerycznych układu z prostokątnymi kanałami o wymiarach $0.2 \times 0.4 \mathrm{~mm}$ i długości 10 $\mathrm{mm}$ zaprezentowano $\mathrm{w}$ [3]. Z kolei praca [4] dotyczy badań eksperymentalnych metodą bilansu cieplnego dwóch rodzajów mini-wymienników z kanałami o długości $16 \mathrm{~mm}$ i przekroju kwadratowym o boku 0.2 lub $0.1 \mathrm{~mm}$. Badania prowadzone na konstruowanym stanowisku umożliwią weryfikację klasycznej metody bilansu cieplnego poprzez zastosowanie metody prądów granicznych oraz analogii wymiany masy i ciepła w odniesieniu do minikanałów o różnych przekrojach poprzecznych stanowiących elementy miniwymienników. 


\title{
Literatura
}

[1] Bieniasz B.: Konwekcyjna wymiana masy/ciepła w płytkowych wirnikach regeneratora obrotowego, OW Politechniki Rzeszowskiej, Rzeszów 2005.

[2] Celata G. P., Cumo M., Marconi V., McPhail S. J., Zummo G.: Microtube liquid single-phase heat transfer in laminar flow, Int. J. Heat Mass Transfer, 49 (2006) 3538-3546.

[3] Chein R., Chen J.: Numerical study of the inlet/outlet arrangement effect on microchannel heat sink performance, Int. J. Thermal Sci., 48 (2009) 1627-1638.

[4] Garcia N., Acosta-Iborra A., Ruiz-Rivas U., Izquierdo M.: Experimental investigation of fluid flow and heat transfer in a single-phase liquid flow micro-heat exchanger, Int. J. Heat Mass Transfer, 52 (2006) 5433-5446.

[5] Wetly J. R., Wicks C. E., Wilson R. E., Rorrer G. L.: Fundamentals of momentum, heat and mass transfer, John Wiley \& Sons, Inc. 2007.

[6] Wilk J.: Experimental investigation of convective mass/heat transfer in short minichannel at low Reynolds numbers, Exp. Thermal Fluid Sci., 33 (2009) 267-272.

[7] Wilk J.: Convective mss/heat transfer in the entrance region of the short circular minichannel, Exp. Thermal Fluid Sci., 38 (2012) 107-114.

[8] Wiśniewski S., Wiśniewski T. S.: Wymiana ciepła. WNT, Warszawa 1994.

\section{CONCEPT OF THE STAND FOR MEASUREMENTS OF MASS AND HEAT TRANSFER COEFFICIENTS IN MINI HEAT EXCHANGERS}

\begin{abstract}
S u m m a r y
The paper presents the preliminary conception of the experimental stand for measurements of mass and heat transfer coefficients in mini heat exchangers. The proposed method based on the electrolytic technique in which to determine the mass transfer coefficients the equations describing the electrolysis phenomenon are used. Measurements of limiting streams established, the cathode surface at which the ion exchange exists, and the concentration of ions in the electrolyte make it possible to determine the intensity of mass exchange. The proposed method may be used in small scale applications. However, this is connected with the additional conditions that must be met in order to minimize errors resulted from the scale of the process, e.g. the surface roughness of the electrodes, the concentration change of the length of the cathode, or the average thickness of the diffusion layer. Designed test stand will allow to study the intensity of mass and heat exchange in mini exchanger with channels of rectangular cross-section.
\end{abstract}

Keywords: experimental investigations, limiting stream method, minichannels, heat exchange

DOI: $10.7862 / \mathrm{rm} .2014 .38$

Otrzymano/received: 25.05 .2014

Zaakceptowano/accepted: 28.06.2014 